\title{
Erratum to: Investigation of Mg-Y coated gasochromic smart windows for building applications
}

\author{
Runqi Liang', Dingming Liu', Yanyi Sun' $(\varangle)$, Xuanli Luo² (ه), David Grant² ${ }^{2}$ Gavin Walker², Yupeng Wu' \\ 1. Department of Architecture and Built Environment, Faculty of Engineering, University of Nottingham, Nottingham, NG7 2RD, UK \\ 2. Advanced Materials Research Group, Faculty of Engineering, University of Nottingham, Nottingham, NG7 2RD, UK \\ @ The Author(s) 2018 \\ Erratum to \\ BUILD SIMUL \\ DOI 10.1007/s12273-018-0483-3
}

The Acknowledgement statement of the original article was published with missing sponsors information. The updated statement is shown below:

\section{Acknowledgements}

This work was funded by the Innovate UK Research Project E-IPB-TS/P009263/1-102880. Xuanli Luo acknowledges the support of a Daphne Jackson Trust fellowship and its sponsors: Royal Academy of Engineering and the University of Nottingham. A PhD studentship from the Faculty of Engineering, the University of Nottingham was awarded to Runqi Liang.

The online version of the original article can be found at

https://doi.org/10.1007/s12273-018-0483-3

\section{Open Access:}

This article is licensed under a Creative Commons Attribution 4.0 International License, which permits use, sharing, adaptation, distribution and reproduction in any medium or format, as long as you give appropriate credit to the original author(s) and the source, provide a link to the Creative Commons licence, and indicate if changes were made.

The images or other third party material in this article are included in the article's Creative Commons licence, unless indicated otherwise in a credit line to the material. If material is not included in the article's Creative Commons licence and your intended use is not permitted by statutory regulation or exceeds the permitted use, you will need to obtain permission directly from the copyright holder.

To view a copy of this licence, visit http://creativecommons.org/licenses/by/4.0/.

E-mail: Yanyi.Sun@nottingham.ac.uk (Yanyi Sun); Xuanli.Luo@nottingham.ac.uk (Xuanli Luo) 